\title{
Sherlock Holmes wissenschaftlich überprüft
}

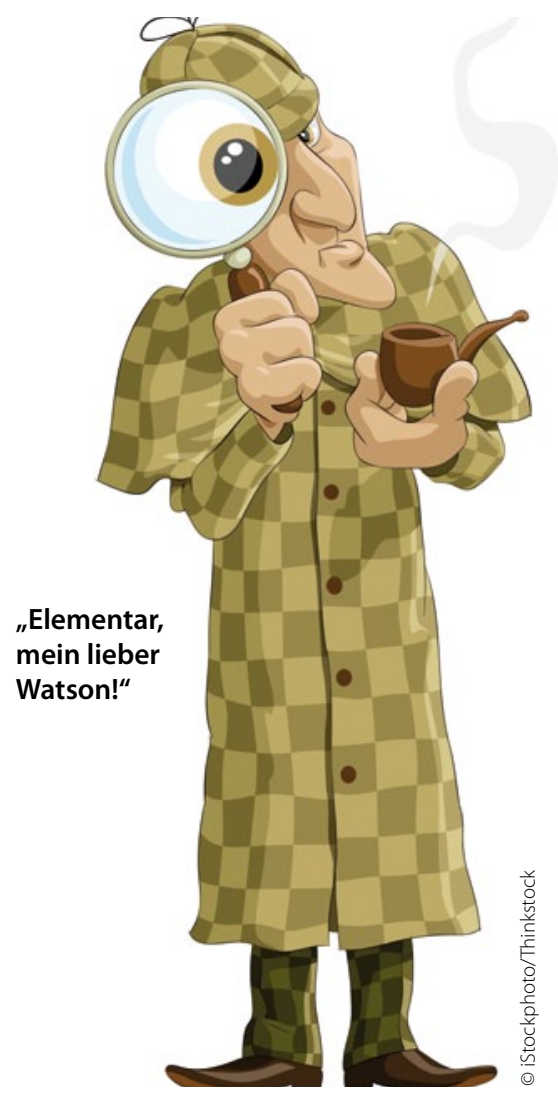

Eine wissenschaftlich exakte Untersuchung zu einem winzigen Detail in einem Sherlock-Holmes-Roman zeigt, dass der Autor, wie fast immer, durchaus richtig lag.

— „Es ist ein Mord geschehen, und der Mörder war ... größer als 1,80 m". In seinem Kriminalroman „Eine Studie in Scharlachrot" beschreibt Sir Arthur Conan Doyle, wie die Leiche eines ermordeten Mannes in einem verlassenen Haus gefunden wird, wo auf eine Wand mit Blut das deutsche Wort „RACHE“ geschrieben wurde. Holmes betrachtete die Fußspuren im Staub und die blutige Inschrift. Danach kommt er zu dem oben zitierten Schluss.

Wie er dem lieben Watson erklärt, hängt die Schrittlänge eines Mannes von seiner Größe ab (Fußspuren). Und: „Wenn ein Mensch an der Wand schreibt, schreibt er instinktiv etwa in der Höhe seiner eigenen Augen. Nachdem sich die Schrift etwa in 1,80 m Hö- he über dem Boden befand, war es nur ein Kinderspiel."

Ob diese Behauptung zutrifft, wurde nun an 100 Freiwilligen untersucht, die man bat, das Wort „RACHE“ auf ein großes Schaufenster zu schreiben. Dabei zeigte sich, dass Holmes Bemerkung meist zutrifft. Lediglich sehr kleine Probanden schreiben über und sehr große unter ihrer Augenhöhe.

- Ruder T. D. et al.

(Korres.: thomas.ruder@hotmail.com): The writing's on the wall for Sherlock Brit. Med. J. 2011; 343: d7406

\section{AchtUng:}

\section{Hier muss der Dummy durch eine Anzeige ersetzt werden !!}

